\title{
Confounding factors in the diagnosis and clinical course of rare congenital hemolytic anemias
}

\author{
Bruno Fattizzo ${ }^{1,2^{*}} \mathbb{D}$, Juri Alessandro Giannotta ${ }^{1}$, Nicola Cecchi ${ }^{2}$ and Wilma Barcellini ${ }^{1}$
}

\begin{abstract}
Congenital hemolytic anemias (CHAs) comprise defects of the erythrocyte membrane proteins and of red blood cell enzymes metabolism, along with alterations of erythropoiesis. These rare and heterogeneous conditions may generate several difficulties from the diagnostic point of view. Membrane defects include hereditary spherocytosis and elliptocytosis, and the group of hereditary stomatocytosis; glucose-6-phosphate dehydrogenase and pyruvate kinase, are the most common enzyme deficiencies. Among ultra-rare forms, it is worth reminding other enzyme defects (glucosephosphate isomerase, phosphofructokinase, adenylate kinase, triosephosphate isomerase, phosphoglycerate kinase, hexokinase, and pyrimidine 5'-nucleotidase), and congenital dyserythropoietic anemias. Family history, clinical findings (anemia, hemolysis, splenomegaly, gallstones, and iron overload), red cells morphology, and biochemical tests are well recognized diagnostic tools. Molecular findings are increasingly used, particularly in recessive and de novo cases, and may be fundamental in unraveling the diagnosis. Notably, several confounders may further challenge the diagnostic workup, including concomitant blood loss, nutrients deficiency, alterations of hemolytic markers due to other causes (alloimmunization, infectious agents, rare metabolic disorders), coexistence of other hemolytic disorders (autoimmune hemolytic anemia, paroxysmal nocturnal hemoglobinuria, etc.). Additional factors to be considered are the possible association with bone marrow, renal or hepatic diseases, other causes of iron overload (hereditary hemochromatosis, hemoglobinopathies, metabolic diseases), and the presence of extra-hematological signs/ symptoms. In this review we provide some instructive clinical vignettes that highlight the difficulties and confounders encountered in the diagnosis and clinical management of CHAs.
\end{abstract}

Keywords: Congenital hemolytic anemias, Iron overload, Splenectomy, Molecular studies, Differential diagnosis

\section{Introduction}

Congenital hemolytic anemias (CHAs) are rare diseases that comprise defects of the erythrocyte membrane proteins and of red blood cell (RBC) enzymes metabolism, along with alterations of erythropoiesis. These are very heterogeneous conditions both clinically and regarding genetic inheritance, arising several concerns from the

${ }^{*}$ Correspondence: bruno.fattizzo@unimi.it

${ }^{1}$ Hematology Unit, Fondazione IRCCS Ca' Granda Ospedale Maggiore Policlinico, Milan, Italy

Full list of author information is available at the end of the article diagnostic point of view. Clinically, CHAs are characterized by variable degree of anemia (from fully compensated to intra-uterine death) and hemolysis, increased erythrocyte turnover, splenomegaly, jaundice, biliary lithiasis, and iron overload. Beyond the pivotal importance of red cells morphology, the diagnosis is facilitated by family history in dominant conditions, whilst it is mainly based on biochemical and molecular findings in recessive and de novo cases. The typical examples of membrane defects are hereditary spherocytosis (HS), hereditary elliptocytosis (HE), and the group of hereditary stomatocytosis (Hst), which are mostly dominant original author(s) and the source, provide a link to the Creative Commons licence, and indicate if changes were made. The images or other third party material in this article are included in the article's Creative Commons licence, unless indicated otherwise in a credit line to the material. If material is not included in the article's Creative Commons licence and your intended use is not permitted by statutory regulation or exceeds the permitted use, you will need to obtain permission directly from the copyright holder. To view a copy of this licence, visit http://creativecommons.org/licenses/by/4.0/. The Creative Commons Public Domain Dedication waiver (http://creativeco mmons.org/publicdomain/zero/1.0/) applies to the data made available in this article, unless otherwise stated in a credit line to the data. 
$[1,2]$. Table 1 shows the genetic basis of most common membrane defects. Glucose-6-phosphate dehydrogenase (G6PD) and pyruvate kinase (PK), are the most common enzyme deficiencies, showing an X-linked and recessive inheritance, respectively. Among rarer $\mathrm{CHAs}$, it is worth mentioning several ultra-rare enzyme defects (glucosephosphate isomerase, GPI, phosphofructokinase, PFK, adenylate kinase, AK, triosephosphate isomerase,
TPI, phosphoglycerate kinase, PGK, hexokinase, HK, and pyrimidine $5^{\prime}$-nucleotidase, $\mathrm{P} 5 \mathrm{~N}$ ), and congenital dyserythropoietic anemias (CDA), mostly recessive conditions. Table 2 shows the genetic basis of the listed enzymatic defects and CDAs [3-7]. The diagnosis of CHAs is sometimes challenging, due to their rarity, their variable phenotype, and the need of specialized work-up and genetic testing. Moreover, several confounders should be

Table 1 Genetic basis of red blood cell membrane defects

\begin{tabular}{|c|c|c|c|}
\hline & Trasmission & Gene & Function \\
\hline \multirow[t]{5}{*}{ Hereditary spherocytosis (HS) } & Autosomal recessive & SPTA1 & Membrane skeletal network \\
\hline & Autosomal dominant & SPTB & Membrane skeletal network \\
\hline & Autosomal dominant & $S L C 4 A 1$ & $\begin{array}{l}\text { Anion exchange channel } \\
\text { Link to glycoltytic enzymes } \\
\text { Vertical interactions }\end{array}$ \\
\hline & Autosomal dominant, de novo & ANK1 & Vertical interactions \\
\hline & Autosomal recessive & EPB42 & Stabilize band3/ankyrin complex \\
\hline \multirow[t]{3}{*}{ Hereditary elliptocyosis (HE) } & Autosomal dominant & SPTA1 & Membrane skeletal network \\
\hline & Autosomal dominant & SPTB & Membrane skeletal network \\
\hline & Autosomal dominant & EPB41 & Stabilize spectrin-ankyrin contact \\
\hline Hereditary pyropoikylocytosis & Autosomal recessive & $\begin{array}{l}\text { SPTA1/SPTA } 7^{\text {LELY }} \\
\text { SPTA1/SPTB } \\
\text { SPTB/SPTB }\end{array}$ & Membrane skeletal network \\
\hline \multicolumn{4}{|l|}{ Hereditary stomatocytosis (HSt) } \\
\hline Dehydrated & autosomal dominant & PIEZO1 & Mechanosensitive ion channel \\
\hline Overhydrated & autosomal dominant & RHAG & Rh -blood group \\
\hline Gardos Channelopathy & autosomal dominant, de novo & KCNN4 & Potassium Ca2 +-Activated Channel \\
\hline
\end{tabular}

Table 2 Genetic basis of red blood cell (RBC) enzymopathies and congenital dyserythropoietic anemia

\begin{tabular}{|c|c|c|c|}
\hline & Trasmission & Gene & Function \\
\hline \multicolumn{4}{|l|}{ RBC enzyme defects } \\
\hline $\begin{array}{l}\text { Glucose-6-phosphate } \\
\text { Dehydrogenase deficiency (G6PD) }\end{array}$ & X-linked & G6PD & Hexose-monophosphate shunt \\
\hline Pyruvate kinase deficiency (PKD) & Autosomal recessive & $P K-L R$ & Glycolysis \\
\hline Glucosephosphate isomerase deficiency (GPID) & Autosomal recessive & GPI & Glycolysis \\
\hline Triosephosphate isomerase deficiency (TPID) & Autosomal recessive & TPl1 & Glycolysis \\
\hline Hexokinase deficiency (HKD) & Autosomal recessive & $H K 1$ & Glycolysis \\
\hline Phosphofructokinase deficiency (PFKD) & Autosomal recessive & $\begin{array}{l}\text { PFK-M } \\
\text { PFK-L }\end{array}$ & Glycolysis \\
\hline Phosphoglycerate kinase deficiency (PGKD) & x-linked & PGK1 & Glycolysis \\
\hline Pyrimidine-5'-nucleotidase deficiency (P5N) & Autosomal recessive & NT5C3A & Nucleotide metabolism \\
\hline Adenylate kinase deficiency (AKD) & Autosomal recessive & AK1 & Nucleotide metabolism \\
\hline \multicolumn{4}{|l|}{ Congenital dyserythropoietic anemias } \\
\hline CDA type I & Autosomal recessive & $\begin{array}{l}\text { CDAN1 } \\
\text { C15ORF41 }\end{array}$ & $\begin{array}{l}\text { Microtubule attachments } \\
\text { Restriction endonuclease }\end{array}$ \\
\hline CDA type ॥ & Autosomal recessive & SEC23B & Vescicle trafficking \\
\hline CDA type III & Autosomal dominant & KIF23 & Cytokinesis \\
\hline \multirow[t]{2}{*}{ CDA variants } & x-linked & GATA1 & Transcription factor \\
\hline & Autosomal dominant & $K L F 1$ & Transcriptional activator \\
\hline
\end{tabular}


considered, including concomitant blood loss, vitamin/ iron deficiency, alterations of hemolytic markers due to other causes, coexistence of other hemolytic disorders, and association with bone marrow, renal or hepatic diseases. Figure 1 highlights the diagnostic flow chart of the most common CHAs, along with the most frequent confounding factors, and Table 3 illustrates the main diagnostic features. In this review we will provide some instructive clinical vignettes that highlight the difficulties and confounders encountered in the diagnosis and clinical management of CHAs.

\section{Hereditary spherocytosis (HS) and rarer membrane defects}

HS is the most common CHAs in Caucasians, with an estimated prevalence ranging from 1-2/5000. Approximately $75 \%$ of cases display an autosomal dominant pattern of inheritance $[1,2,8,9]$. The molecular defect involves the genes coding for RBC membrane proteins ANK1 (ankyrin, 50-60\% of HS patients), SPTA1 or SPTB ( $\alpha$ - or $\beta$-spectrin, $20 \%$ of HS, taken together), SLC4A1 (band 3, 15-20\% of cases), and EPB42 (protein 4.2 ), the latter being mutated in autosomal recessive HS, more common in Japan but rarer in other populations (Table 1). In about $10 \%$ of HS it is not possible to identify any molecular basis for the disease [9]. A genotype-phenotype correlation may be drawn only to a certain extent in HS, with $\alpha$-spectrin deficiency associated to more severe anemia and remaining mutations displaying a variable degree of anemia. These abnormalities result in loss of RBC membrane surface area, transformation of RBC from discocytes into spheroidal, osmotically fragile cells that are selectively destroyed in the spleen [1]. Clinically, variable degree of anemia, jaundice, splenomegaly and gallstones are the typical findings. Laboratory parameters include increased absolute number of reticulocytes, unconjugated hyperbilirubinemia, and lactate dehydrogenase (LDH), and reduced haptoglobin. The diagnosis is based on family history, RBC morphology, and on the increased osmotic fragility; further useful tests comprise flow cytometric test with eosin 5 maleimide (EMA binding), RBC deformability curve in ektacytometry, and study of membrane proteins in polyacrylamide gel (SDS-PAGE) [10, 11]. Molecular studies are usually not performed, since mutations in HSrelated genes are dispersed and nonspecific as assessed by novel next generation sequencing studies [12, 13]. Given the heterogenous presentation, HS has been classified in classified in trait (normal $\mathrm{Hb}$ and reticulocytes, unconjugated bilirubin $<1 \mathrm{mg} / \mathrm{dL}$ ), mild $(\mathrm{Hb}>11 \mathrm{~g} / \mathrm{dL}$, reticulocytes $3-6 \%$, unconjugated bilirubin $1-2 \mathrm{mg} / \mathrm{dL}$ ), moderate (Hb 8-12 g/dL, reticulocytes 6-10\%, unconjugated bilirubin $>2 \mathrm{mg} / \mathrm{dL})$ and severe $(\mathrm{Hb}>8 \mathrm{~g} / \mathrm{dL}$, reticulocytes $>10 \%$, unconjugated bilirubin $>3 \mathrm{mg} / \mathrm{dL}$ ) [9]. Clinical management of HS mostly relies on folic acid supplementation, especially during infectious or surgical triggers, and splenectomy, when indicated according to the severity of anemia (see below). As for all other CHAs, intrinsically prone to gallstone formation, cholecystectomy is indicated in case of symptomatic lithiasis, and often performed concomitantly with splenectomy [14]. Finally, it is worth mentioning other rarer membrane defects such as HE and Hst that are diagnosed through the same work up suggested for HS, except for HSt that benefit from molecular evaluation. Specifically, HSt are a group of rare hemolytic anemias with autosomal dominant transmission, characterized by the inability to regulate the RBC cation homeostasis. Loss of cation content results in cell dehydration (dehydrated HSt), the most frequent form, caused by gain of function mutations in PIEZO1 gene [15-17]. Other forms include overhydrated HSt, due to mutations in RHAG gene that cause an increase of intracellular water content [18] and the recently described Gardos channelopathy, due to KCNN4 gene mutations that determine a modification of intracellular calcium concentration [16, 19] (Table 1).

\section{Clinical vignette 1: a typical clinical presentation of hereditary spherocytosis}

A 53-year-old male presented with splenomegaly (19.3 $\mathrm{cm}$ at abdomen ultrasound) and altered hemolytic markers. Iron and vitamin levels were normal, no blood loss was documented, direct anti-globulin test (DAT), and hemoglobin $(\mathrm{Hb})$ electrophoresis did not reveal pathological findings. Family history was unremarkable, and the subject had undergone cholecystectomy at the age of 27 years. The laboratory workup (RBC morphology, increased osmotic fragility, positive EMA binding,

(See figure on next page.)

Fig. 1 Diagnostic flow chart and possible confounders in congenital hemolytic anemias (CHAs). RBC: red blood cell, DAT: direct antiglobulin test, HPLC: high performance liquid chromatography, EMA-binding: eosin-5'-maleimide-labeled RBC by flow cytometric analysis, HS: hereditary spherocytosis, HE: hereditary elliptocytosis, HSt: hereditary stomatocytosis, CDA: congenital dyserythropoietic anemia, G6PD: glucose-6-phosphate dehydrogenase, PK: pyruvate kinase, GPI: glucose phosphate isomerise, PFK: phosphofructokinase, TPI: triose phosphate isomerase, PGK: phosphoglycerate kinase, HK: hexokinase, AK: adenylate kinase, P5N: pyrimidine 5'-nucleotidase deficiency. AlHA: autoimmune hemolytic anemia; DTR, delayed transfusion reaction, BM: bone marrow, PNH paroxysmal nocturnal hemoglobinuria, BMF bone marrow failure, AA aplastic anemia, MDS myelodysplastic syndrome 


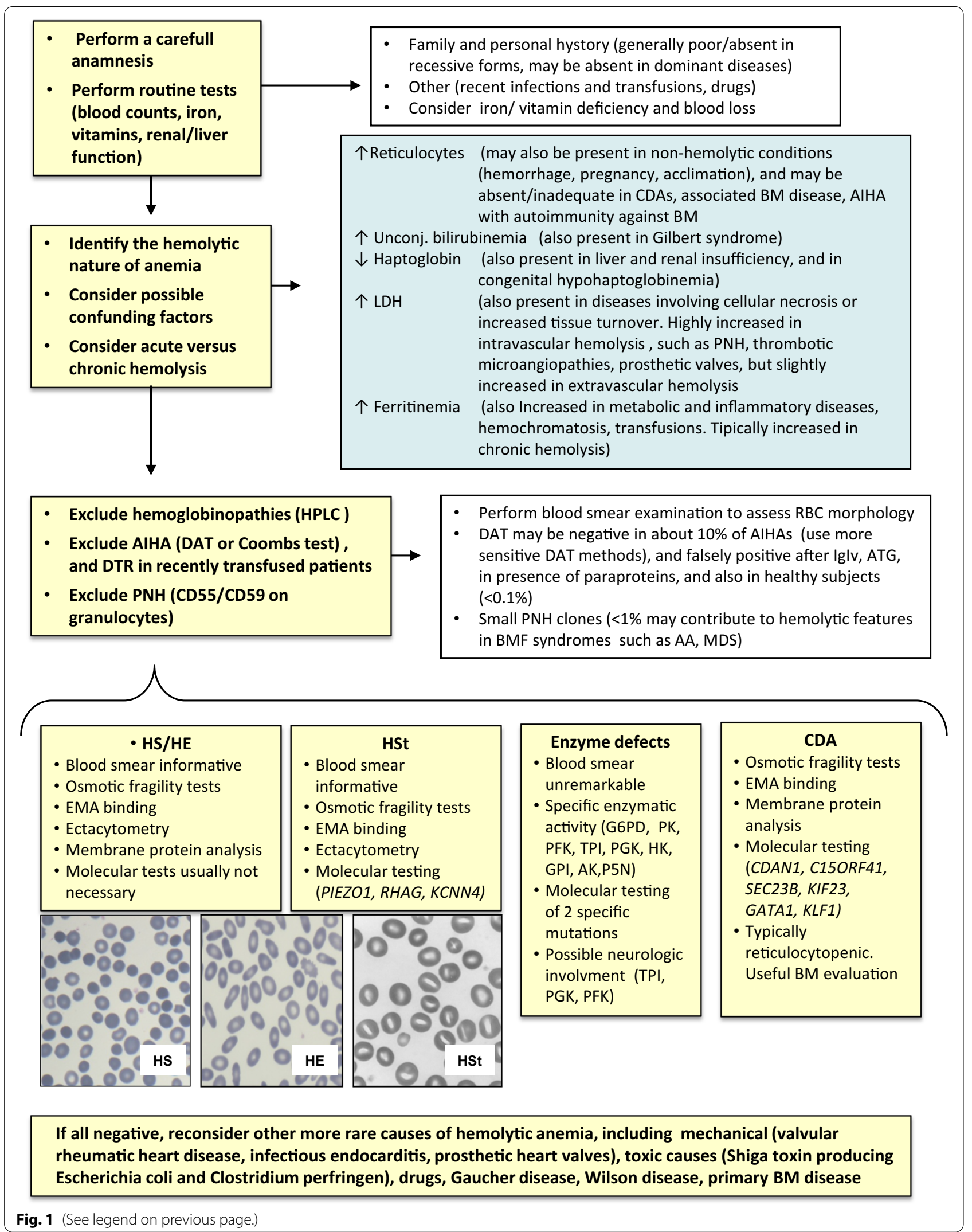


Table 3 Main diagnostic features of congenital hemolytic anemias (CHAS)

\begin{tabular}{|c|c|c|c|}
\hline & Membrane defects & Enzyme defects & Congenital dyserythropoietic anemia \\
\hline Anemia & $\begin{array}{l}\text { Highly variable from severe to normal } \\
\mathrm{Hb} \text { values }\end{array}$ & $\begin{array}{l}\text { Highly variable from severe to normal } \\
\mathrm{Hb} \text { values }\end{array}$ & $\begin{array}{l}\text { Highly variable from very severe to } \\
\text { nearly normal } \mathrm{Hb} \text { values }\end{array}$ \\
\hline Reticulocytes & $\begin{array}{l}\text { Usually elevated except during } \\
\text { aplastic crisis }\end{array}$ & $\begin{array}{l}\text { Usually elevated except during aplas- } \\
\text { tic crisis; particularly elevated in PKD } \\
\text { after splenectomy }\end{array}$ & Usually low as referred to $\mathrm{Hb}$ values \\
\hline Red cell morphology & Highly characteristic & Usually unremarkable & Usually unremarkable \\
\hline $\begin{array}{l}\text { Osmotic fragility tests, EMA } \\
\text { binding, and ectacytometry }\end{array}$ & Typically altered & Usually uninformative & Usually uninformative \\
\hline Membrane protein analysis & Informative in most cases & Useless & $\begin{array}{l}\text { Usually uninformative, except for band } 3 \\
\text { deglycosylation in CDA type II }\end{array}$ \\
\hline Enzyme assays & Useless & Essential & Useless \\
\hline Molecular tests & Informative particularly in HSt & Essential & Essential \\
\hline Family history & Positive in most cases & $\begin{array}{l}\text { Usually negative, consider consan- } \\
\text { guinity }\end{array}$ & $\begin{array}{l}\text { Usually negative, consider consanguin- } \\
\text { ity }\end{array}$ \\
\hline
\end{tabular}

Eosin 5 maleimide EMA binding; PKD pyruvate kynase deficiency; HSt hereditary stomatocytosis; CDA congenital dyserythropoietic anemia

and ektacytometry) led to the diagnosis of HS trait (normal $\mathrm{Hb}$, reticulocytes, and bilirubin), and the patient was followed, always displaying normal Hb levels. Six years later, $\mathrm{Hb}$ levels progressively worsened until $8.4 \mathrm{~g} / \mathrm{dL}$ (requiring transfusion support) along with neutropenia $\left(0.6 \times 10^{9} / \mathrm{L}\right)$ and mild thrombocytopenia $\left(120 \times 10^{9} / \mathrm{L}\right)$. Reticulocyte counts were increased $\left(200 \times 10^{9} / \mathrm{L}\right)$ as well as unconjugated bilirubin $(2.1 \mathrm{mg} / \mathrm{dL})$ and haptoglobin was reduced. The DAT was again negative, as was the research of paroxysmal nocturnal hemoglobinuria $(\mathrm{PNH})$ clone. Once excluded secondary causes (nutrients deficiencies, bleeding, chronic renal/liver diseases and inflammatory conditions), a bone marrow evaluation was performed. The latter showed no features of bone marrow failure/dysplasia, and the subject was vaccinated against capsulated bacteria before splenectomy.

\section{Comments to vignette 1}

The clinical course depicted in this vignette is quite unusual as the severity of HS is generally observed during infancy and adolescence, concomitantly to infections and increased metabolic requests. Here, additional causes of hemolytic anemia and lack of bone marrow compensations were considered, as the subject was middle-aged. Bone marrow evaluation is not routinely performed in membrane and enzyme defects, but its involvement should be taken into account as it can be a confounder in the interpretation of the clinical picture and reduce the efficacy of splenectomy. The latter is usually of high effectiveness in HS, leading to a median Hb increase of $3 \mathrm{~g} /$ $\mathrm{dL}$, associated with an amelioration of hemolytic markers $[10,14]$. It is generally indicated in severe cases during adolescence (always after 5-6 years of age) and in case of symptomatic/painful splenomegaly. Additional findings to be considered are associated thrombocytopenia or leucopenia, and patient's quality of life. For young adult subjects, unacceptable cutaneous jaundice and wish to become pregnant may balance the decision towards splenectomy. It is important to remember that splenectomy is accompanied by an infectious and thrombotic risk and has a greater risk in the elderly [20-23]. Thus, it must be preceded by anti-pneumococcal, anti-meningococcal, and anti-Haemophilus vaccine prophylaxis. Moreover, a prompt referral to the medical attention in case of suspected thrombosis or severe infections is mandatory. Of note, the possible existence of ectopic splenic tissue / accessory spleens may account for relapsing anemia after splenectomy.

Clinical vignette 2: a case of $\mathrm{HS}$ and autoimmune hemolytic anemia (AlHA)

A 22-year-old female from Indian origin was referred to our center with a diagnosis of autoimmune hemolytic anemia (Hb $8.9 \mathrm{~g} / \mathrm{dL}$, LDH $2 \times$ upper limit of normality, DAT positive for IgG) and increased spleen volume (19 $\mathrm{cm}$ at ultrasound). She had been treated with prednisone $1 \mathrm{mg} / \mathrm{Kg}$ day with partial response, followed by rituximab due to early relapse, again with partial response. At referral, a further $\mathrm{Hb}$ decrease was noted $(8.5 \mathrm{~g} / \mathrm{dL})$ and splenectomy was considered. Given the young age, the presence of splenomegaly and gallstones, family history was reevaluated, although difficult to collect due to language barrier. A mild anemia was noted during adolescence and neonatal jaundice referred. Blood smear analysis revealed the presence of spherocytes which, although possibly present in AIHA, prompted the examination of a possible CHA. Osmotic fragility test and EMA-binding were consistent with a diagnosis of 
HS, but ektacytometry showed a pattern suspicious for dehydrated HSt. Therefore, mutational analysis for HSt genes was performed and returned negative. The patient underwent splenectomy and cholecystectomy with complete recovery of her anemia of both causes, autoimmune and congenital.

\section{Comment to vignette 2}

Although AIHA is rarely observed together with $\mathrm{CHAs}$ due to membrane defects, several reports have been described of AIHA complicating congenital anemias, including thalassemia and sickle cell disease [24, 25]. Thus, DAT should always be evaluated not only at diagnosis, but also performed during the follow up, particularly in case of unexpected $\mathrm{Hb}$ drop. Therapy of AIHA includes steroids, rituximab, and splenectomy. Since the latter therapeutic option was adopted, the patient has been extensively studied to exclude a diagnosis of HSt, given the increased thrombotic risk observed in this condition after splenectomy, that is contraindicated particularly in the dehydrated form [14, 26-28]. The case also highlights that ektacytometry is pivotal in the differential diagnosis of membrane defects. However, it is worth mentioning that "secondary" spherocytosis is observed also in AIHA, due to partial phagocytosis of autoantibody-bound RBCs, so that ektacytometry pattern may be indistinguishable from HS.

\section{Pyruvate kinase deficiency (PKD)}

PKD is the most frequent non-spherocytic CHA (estimated prevalence of $3-8$ per $1,000,000$ ) caused by autosomal recessive variants in the $P K L R$ gene. PKD is highly heterogeneous from a biochemical, clinical and genetic point of view, since over 300 pathogenic mutations in the PKLR gene have been described so far [7]. The diagnosis should be suspected in the presence of clinical signs and symptoms and laboratory markers of chronic hemolytic anemia and is based on the demonstration of reduced PK enzymatic activity, and on the detection of compound heterozygous or homozygous mutations in the PKLR gene $[29,30]$. Enzymatic activity may give falsely normal levels in the presence of an increased number of reticulocytes, recent transfusions, or incomplete removal of platelets or white blood cells. Thus, the diagnosis should be confirmed by PKLR genotyping: more common mutations are missense substitutions, while disruptive mutations (stop codons, frameshifts, and large deletions) are less frequent and generally associated with a more severe phenotype [7, 31]. Advantages of the genetic testing are the small blood volume required, no interference by transfused RBCs, and suitability for prenatal diagnosis. Disadvantages are the difficulty to identify large deletions and intronic mutations, and the interpretation of newly reported mutations as causative without functional tests. Therefore, both PK enzyme activity and PKLR genetic testing are recommended to confirm the diagnosis of PKD [29, 30]. Clinical presentation is highly variable, ranging from hydrops fetalis and prematurity, to fully compensated hemolysis (indirect hyperbilirubinemia or reticulocytosis) without anemia. Most subjects receive at least one transfusion, particularly during infancy/adolescence and generally during infectious episodes. About $20 \%$ of patients are transfusion-dependent, and contrarily to HS, splenectomy (performed in more than half of cases) only slightly ameliorates anemia (median rise in $\mathrm{Hb}$ of $1.6 \mathrm{~g} / \mathrm{dl}$ ). In addition, transfusion dependence persists in $10 \%$ of patients even after splenectomy [30, 31]. Bone marrow transplant has been only anecdotally reported, with high toxicity, and is not generally pursued. Experimental new treatments are in progress, including an oral activator of $\mathrm{PK}$ enzyme (mitapivat) and gene therapy [32, 33] (NCT04105166). Complications are frequent and include iron overload (48\%), gallstones (45\%), thrombosis (11\%), and more rarely osteopenia, aplastic crisis, extramedullary hematopoiesis, endocrine disfunction, pulmonary hypertension and leg ulcers [31, 34, 35].

\section{Clinical vignette 3: a severe PKD with alloimmunization}

A 19-year-old male had been diagnosed with severe PKD since infancy and regularly transfused (1 RBC unit every 1-2 months). Transfusion burden persisted even after splenectomy performed at 6 years of age. He was on regular chelation because of iron overload and suffered from several infections. He was referred due to increased transfusion need and drop of pre-transfusion $\mathrm{Hb}$ levels. An aplastic crisis was excluded given increased reticulocytes (typically observed in splenectomized PKD) and platelets, and negative infectious screening (Parvovirus B19, cytomegalovirus, Epstein-Barr virus, etc.). DAT and indirect anti-globulin test (IAT) were both positive and further investigation led to the identification of alloantibodies anti-Fy.

\section{Comment to vignette 3}

A possible complication of transfusions is the development of alloantibodies. The latter generally show an evanescent pattern so that only about $30 \%$ are usually detected. Their clinical significance is variable and largely depends on the amount of transfused RBCs and on their type and titer. The most common blood groups involved in alloimmunization are Rh, Kell, Duffy, and Kidd and the relative antigens (CDEec, $\mathrm{KkJs}^{\mathrm{a}}, \mathrm{Jk}^{\mathrm{a}} \mathrm{Jk}^{\mathrm{b}}$, $\left.\mathrm{Fy}^{\mathrm{a}} \mathrm{Fy}^{\mathrm{b}}, \mathrm{Lu}^{\mathrm{a}} \mathrm{Lu}^{\mathrm{b}}, \mathrm{MNSs}\right)$. These alloantibodies may cause increased hemolysis that might falsely be attributed to the underlying $\mathrm{CHA}$ and may result in augmented transfusion need. Alloantibodies should be excluded 
with absorption techniques and extended phenotyping/ genotyping of the above cited antigens [36]. Genotyping is currently recognized as the preferred technique allowing the selection of the best antigen-matched units [37]. A good communication between the clinician and the transfusion center is advisable in transfusion dependent cases.

\section{Glucose-phosphate isomerase deficiency (GPID)}

GPID is the second most common enzymopathy of glycolysis, following PKD. It usually causes mild to severe chronic hemolytic anemia and rarely intellectual disability or neuromuscular symptoms [6, 38-41]. GPID is transmitted as an autosomal recessive trait and gene locus is located on chromosome 19q13.1 [42]. About 60 patients with GPID have been described, and about 40 mutations have been reported so far. Missense mutations are the most common, but non-sense and splicing mutations have also been observed. A series of 12 subjects with GPID has been recently reported, showing a median age at diagnosis of 13 years (1-51), displaying moderate to severe anemia that improved with aging, and no neurological symptoms. Serum ferritin levels were increased in most patients and two of them required iron chelation. Six novel mutations in the GPI gene were identified and were considered pathogenic [6].

\section{Clinical vignette 4: A case of GPID with iron overload}

A 42-year-old male was referred for chronic hemolytic anemia since infancy with a presumed diagnosis of congenital membrane defect and iron overload (ferritin levels $2346 \mathrm{ng} / \mathrm{mL}$, and transferrin saturation of 89\%). During childhood transfusion dependence was present and splenectomy was performed at 9 years of age obtaining transfusion independence. Moreover, cholecystectomy was performed at the age of 15 due to frequent abdominal pain. Family history was unremarkable, although parents might have been distant relatives (originating from a small village). Screening for membrane defects was normal, and enzymatic testing revealed a GPI deficiency (32\% enzymatic residual activity), while other enzymes (G6PD, PK, PFK, AK, PGK, TPI, HK, and P5N) were normal. Molecular analysis confirmed the diagnosis, by showing two compound mutations. Testing for hereditary hemochromatosis gave negative results, and $\mathrm{T} 2$ * MRI study showed a moderate iron overload (liver iron concentration $>4 \mathrm{mg} \mathrm{Fe} / \mathrm{g}$ dry weight). Oral iron chelation was started with progressive amelioration of iron parameters and normalization within 1 year of therapy. Chelation was stopped and cyclically resumed, monitoring ferritin levels and transferrin saturation.

\section{Comment to vignette 4}

Given the rarity of GPID, the diagnosis was delayed of several years and was reached only at a reference center where biochemical tests and molecular tools for rarer enzymopathies were available. The peculiarity of this case is the important iron overload, that may be observed in all CHAs, and that is partly explained by the transfusion dependence in severe anemic patients. Iron overload is poorly considered in CHAs, at variance with hemoglobinopathies and the possible coexistence of hereditary hemochromatosis should always been investigated. In fact, even a heterozygous state for the latter, combined with chronic hemolysis, may result in iron overload. A recent study evaluated cardiac and hepatic MRI in subjects with different CHAs and found iron overload found in $40 \%$ of patients. The association of ferritin $>500 \mu \mathrm{g} / \mathrm{L}$ plus transferrin saturation $>60 \%$ was demonstrated as the best combination to predict MRI findings. Iron overload was also associated with increased erythropoietin and hepcidin values and with augmented inflammatory cytokine levels, suggesting the existence of a vicious cycle between chronic hemolysis, inflammatory response and iron in CHAs [6]. Iron chelation and its monitoring are only partially defined in patients with CHAs and most clinicians rely on the experience of hemoglobinopathies. The monitoring of serum ferritin and transferrin saturation appears cost effective, whereas no clear indications for sequential MRI assessment are available [43]

\section{Triosephosphate isomerase deficiency (TPID)}

Among ultra-rare enzyme deficiencies, it is worth mentioning a group of conditions where hemolysis is associated with several non-hematologic manifestations. The latter occur when the defective enzyme is not confined to the red cells but also expressed in other tissues, such as in TPI, PGK, PFK, and AK. Clinical features include neurologic impairment, myopathy, and frequent infections, which are variably combined in the different phenotypes. Most of these conditions display recessive inheritance, heterogeneous clinical presentation and severity, challenging the diagnosis. TPI deficient patients nearly always display serious neuromuscular disease and susceptibility to infections, and most of them die in the first decade of life $[3,44,45]$.

\section{Clinical vignette 5: TPID and severe neurological involvement}

A 2-year-old child suffered since birth from severe neurologic dysfunction, with encephalopathy, psychomotor impairment, neuropathy, apostural tetraparesis, and diaphragmatic paralysis. She suffered from several infectious episodes, had been subjected to tracheostomy for 
respiratory insufficiency, to gastrostomy to allow nutrition, and required occasional transfusion support for episodes of anemia. Investigations for congenital metabolic diseases included plasma, urine and cerebrospinal fluid amino acids, urine organic acids, plasma acylcarnitine profile, and urine mucopolysaccharides and oligosaccharides, all resulting within the normal range. Moreover, tests for congenital disorders of glycosylation, as well as bone marrow examination gave no insights into this complex presentation. Thereafter, attention was paid to persistent anemia, and some hemolytic features were noted, although difficult to interpret in the clinical context. At referral, $\mathrm{Hb}$ was $7.4 \mathrm{~g} / \mathrm{dL}$, and peripheral blood smear revealed the presence of dacrocytes, spherocytes, elliptocytes, schistocytes, and target cells. Osmotic fragility tests, EMA-binding and SDS analysis of membrane proteins were normal. Enzymatic activity tests displayed a marked reduction of TPI, whilst G6PD, PK, GPI, PFK, $\mathrm{AK}, \mathrm{PGK}, \mathrm{HK}$, and $\mathrm{P} 5 \mathrm{~N}$ were within the normal range. Molecular studies confirmed the diagnosis of TPI deficiency, by showing a compound heterozygosity in the proband. The same mutations were present in the parents at heterozygous state.

\section{Comment to vignette 5}

As also shown in the clinical vignette 4, the diagnosis of ultrarare enzymatic deficiencies relies on specialized analyses that are available only in few dedicated laboratories. In the case described, the diagnosis was particularly challenging given the extra-hematological manifestations that puzzled clinical picture. Overall, this vignette highlights the importance of deepening the diagnostic assessment of hemolytic features noted in individuals with syndromic phenotypes and extra-hematological features. Moreover, molecular characterization of the defect is important to confirm the diagnosis and to allow genetic counseling and prenatal diagnosis in more severe cases.

\section{Congenital dyserythropoietic anemia (CDA)}

CDAs are a group of very rare congenital anemias (prevalence of $1-9$ per $1,000,000)$ marked by ineffective erythropoiesis and morphological abnormalities of erythroblasts. Clinically, anemia and hemolytic features are variable, but usually characterized by inadequate reticulocytosis [5, 46-49]. CDAs classification include three major types (I, II and III) and other rarer variants or sporadic. The identification of these subtypes is based on the typical morphology of bone marrow erythroblasts and, more recently, on the detection of the characteristic mutations $[50,51]$. The latter have also allowed to clarify some of the pathogenic mechanisms affecting cell maturation and division. CDA type I (CDAI), inherited as a recessive disorder, is caused by mutations in CDAN1
(CDAIa) or c15orf41 (CDAIb) genes. Bone marrow is characterized by the presence of binucleated erythroblasts, chromatin bridges between nuclei, and "Swiss cheese" appearance of dense heterochromatin at electron microscopy [52]. CDA type II (CDAII) is also inherited as a recessive disease, and is caused by mutations in the $S E C 23 B$ gene $[53,54]$. Membrane protein investigation demonstrates a typical hypoglycosylation of band 3 , and bone marrow shows binucleated and multinucleated erythroblasts with a peripheral double membrane. CDA type III, differently from the previous forms, has a dominant inheritance, and is caused by mutation of KIF23 [55]. Finally, rarer CDA variants are CDA type IV (associated with the dominantly inherited $K L F 1$ gene mutation) [56] and an X-linked sporadic form caused by GATA 1 mutation [57] (Table 2).

\section{Clinical vignette 6: a case of CDAll and severe bleeding}

A 36-year-old man was referred for moderate macrocytic anemia with inadequate reticulocytosis ( $\mathrm{Hb} 9.8 \mathrm{~g} /$ $\mathrm{dL}$, mean corpuscular volume $106 \mathrm{fL}, 80 \times 10^{9} / \mathrm{L}$ reticulocytes), mild hemolytic features (LDH $1.2 \times$ upper limit of normality, unconjugated bilirubin $1.2 \mathrm{mg} / \mathrm{dL}$, undetectable haptoglobin), and splenomegaly $(18 \mathrm{~cm}$ by ultrasound). Diagnostic workup (negativity of osmotic fragility tests and ektacytometry, normal RBC enzymes assays, hypoglycosylation of band 3, bone marrow dyserythropoiesis, and detection of SEC23B mutation) led to the diagnosis of CDAII and the subject was put on clinical follow up. One year later, $\mathrm{Hb}$ levels progressively decreased to $6-7 \mathrm{~g} / \mathrm{dL}$ requiring prompt transfusion. Additional causes of anemia were investigated with the identification of erosive gastro-duodenitis with chronic/ subacute blood loss. Treatment with proton pump inhibitors led to gastro-duodenitis amelioration and $\mathrm{Hb}$ levels progressively stabilized at about $8 \mathrm{~g} / \mathrm{dL}$. Given the progressive increase of spleen size $(21 \mathrm{~cm}$ diameter) and overall poor quality of life, the patient has been splenectomized obtaining stable $\mathrm{Hb}$ levels between 10.5 and $11.5 \mathrm{~g} / \mathrm{dL}$.

\section{Comment to vignette 6}

This is a typical case with a defined diagnosis of CHA in which a superimposed cause of anemia challenged clinical management. Blood loss is usually accompanied by compensatory reticulocytosis that was not observed in this case due to bone marrow dyserythropoiesis. Moreover, transfusions may also jeopardize the evaluation of bone marrow compensation. Once identified and corrected the blood loss, there was a treatment need for CDAII. Data from literature report that splenectomy is not as effective as in HS, leading to an average $\mathrm{Hb}$ increase of about $1 \mathrm{~g} / \mathrm{dL}[10,14,58]$. Given the 
well-known infectious and thrombotic complications of splenectomy, a clear indication is not easy to establish. Recent recommendations from the European Hematology Association state that splenectomy in CDAII should be considered in severely anemic cases and/or in those with symptomatic splenomegaly [14]. The only curative treatment for severe CDA is hematopoietic stem-cell transplantation, which has been reported only in few pediatric cases with good outcome [59]. Potential future therapies include drugs targeting ineffective erythropoiesis such as sotatercept and luspatercept, that have been shown effective in CDAII murine models, and in thalassemia and myelodysplastic syndromes [60-62].

\section{Undiagnosed CHAs}

Despite extensive and complete morphologic, biochemical, and molecular investigation, about $20 \%$ of CHAs remain undiagnosed. This results in a disappointing burden of consultations and tests for the individuals, disproportional resource utilization, risk of inappropriate therapies such as splenectomy, and preclusion of novel specific treatments such as mitapivat in PKD. The recent availability of next generation sequencing (NGS) technologies has greatly improved the diagnostic approach to CHAs. However, the performance of this technique largely depends on the NGS strategies adopted, including different targeted panels or whole exome sequencing (WES) [63]. The latter are not routinely available and their interpretation still relies on clinical findings.

\section{Clinical vignette 7: a man with undiagnosed $\mathrm{CHAs}$ and Gaucher disease}

A 31-year-old male was referred for mild pancytopenia (Hb $11 \mathrm{~g} / \mathrm{dL}$, PLT $62 \times 10^{9} / \mathrm{L}$, WBC $2.3 \times 10^{9} / \mathrm{L}$ ), splenomegaly (16 cm diameter), and hyperferritinemia (620 ng/ $\mathrm{mL}$ ). These features were present since adolescence, and he had received several consultations and undergone countless investigations without a definite diagnosis. Extensive work up for CHAs (morphology, study of membrane proteins, erythrocyte enzymes, EMA-binding, ectacytometry, and NGS panel) resulted negative. By re-examining the clinical history, a recently implemented algorithm for the diagnosis of Gaucher disease (GD) was considered. The latter relied on two main criteria, i.e. splenomegaly and/or thrombocytopenia associated with at least one among the following: bone pain history, anemia, monoclonal gammopathy of unknown significance, polyclonal gammopathy in subjects under 30 years of age and splenectomy. The subject underwent testing for $\beta$-glucosidase enzyme activity on dried blood spot, resulting positive. The positivity was confirmed by specific genetic analysis (GBA1 gene mutation) and led to the diagnosis of GD.

\section{Comment to vignette 7}

Although splenomegaly is one of the most common characteristics of CHAs, there are many other causes that should be taken into account. They may be classified according to the pathogenic mechanism including increased spleen function, abnormal blood flow, and spleen infiltration. The first group includes CHAs, infections (mononucleosis, viral hepatitis, splenic abscess, typhoid fever, brucellosis, leptospirosis, tuberculosis, histoplasmosis, malaria, leishmaniasis, trypanosomiasis), autoimmune diseases (rheumatoid arthritis, systemic lupus erythematosus, etc.), and extramedullary hematopoiesis. The vascular causes encompass hepatic hypertension (cirrhosis, Budd-Chiari syndrome), and hepatic schistosomiasis and echinococcosis. Finally, infiltrative diseases include neoplastic diseases (leukemias, lymphomas, methastatic solid tumors) and the rare metabolic disorders (GD, Niemann-Pick disease, alpha-mannosidosis, Hurler syndrome and other mucopolysaccharidoses, amyloidosis, and Tangier disease). Despite this broad list, the diagnosis of GD is quite easy provided clinical suspicion. GD is the most common lysosomal hereditary disorder due to the deficiency of the $\beta$-glucosidase enzyme causing the accumulation of glucosylceramide in the reticuloendothelial cells. It is an autosomal recessive disorder with an elevated prevalence in the Ashkenazi Jewish population $(1 / 600$, carrier rate $1 / 15)$ compared to the non-Ashkenazi population (1/75000 births). The application of the above cited diagnostic algorithm led to the diagnosis of GD in 7 out of 196 previously undiagnosed patients, allowing substitutive enzymatic therapy $[64,65]$.

\section{Conclusions}

The diagnosis of CHAs may be challenging due to their rarity, poor knowledge, and to the requirement of specialized diagnostic work-up and genetic testing. Additional difficulties reside in their heterogeneous clinical phenotype, which may include extra-hematologic and neurologic findings, causing referrals to different specialists. This may lead to a delayed diagnosis, with a burden of consultations and tests for the patient, and aconsequent inappropriate healthcare resource utilization. Moreover, incorrect diagnoses may cause inappropriate therapies such as splenectomy in HSt and missed-diagnoses may prevent the access to novel specific treatments such as mitapivat for PKD, or drugs targeting ineffective erythropoiesis in CDAs. New molecular tools, such as NGS and WES, would greatly improve the diagnostic gaps in the near future, provided their broader availability and critical clinical interpretation. Additionally, they can be of great value for genetic counseling, which is increasingly asked by affected families. More importantly, several even 
common confounders should be considered, as highlighted in the clinical vignettes presented. They include the possible coexistence of other diseases, such as mild myelodysplasia in advanced age, which may hamper the bone marrow compensation, or a banal and underestimated blood loss. DAT-positivity due to alloimmunization, which is a fairly common and known finding in hemoglobinopaties, should always be considered in transfusion-dependent CHAs, as well as the coexistence of a true DAT-positive autoimmune hemolytic anemia. Likewise, it is worth considering the presence of hemolysis associated with mechanical injury, toxic agents, and infections, or of small paroxysmal nocturnal hemoglobinuria clones, that may be found in healthy subjects and in several other hematologic diseases [66, 67]. Iron overload is a frequent finding in CHAs, and this underestimated complication may be the main reason for referral. Likewise, isolated splenomegaly may be a reason for referral to the hematologist, leading to investigate boundless infectious, autoimmune and lymphoproliferative/neoplastic conditions to unravel the differential diagnosis. Finally, when an extensive investigation is inconclusive, even diagnoses completely different from CHAs should be taken into account. These include one of the several metabolic disorders, such as GD illustrated in the last vignette. Overall, confounders should always be considered, keeping an open-mind attitude across the several congenital and acquired diseases with hemolytic features, and maintaining a tight interaction between clinicians and laboratory researchers.

\section{Acknowledgements}

Not applicable.

\section{Authors' contributions}

All authors equally contributed to conceiving, writing, and revising the manuscript. All authors read and approved the final manuscript.

\section{Funding}

No sources to declare.

\section{Availability of data and materials}

Not applicable.

\section{Declarations}

Ethics approval and consent to participate

Not applicable.

\section{Consent for publication}

Not applicable.

\section{Competing interests}

All authors declare that they have no conflict of interest.

\section{Author details}

'Hematology Unit, Fondazione IRCCS Ca' Granda Ospedale Maggiore Policlinico, Milan, Italy. ${ }^{2}$ Department of Oncology and Oncohematology, University of Milan, Milan, Italy.
Received: 15 May 2021 Accepted: 19 September 2021

Published online: 09 October 2021

\section{References}

1. Mohandas N, Gallagher PG. Red cell membrane: past, present, and future. Blood. 2008;112:3939-48. https://doi.org/10.1182/blood-2008-07-161166.

2. Iolascon A, Andolfo I, Russo R. Advances in understanding the pathogenesis of red cell membrane disorders. Br J Haematol. 2019;187:13-24. https://doi.org/10.1111/bjh.16126.

3. Fermo E, Bianchi P, Vercellati C, Rees DC, Marcello AP, Barcellini W, Zanella A. Triose phosphate isomerase deficiency associated with two novel mutations in TPI gene. Eur J Haematol. 2010;85:170-3. https://doi.org/10. 1111/j.1600-0609.2010.01451.x.

4. Koralkova P, van Solinge WW, van Wijk R. Rare hereditary red blood cell enzymopathies associated with hemolytic anemia-pathophysiology, clinical aspects, and laboratory diagnosis. Int J Lab Hematol. 2014;36:38897. https://doi.org/10.1111/ijlh.12223.

5. Gambale A, Iolascon A, Andolfo I, Russo R. Diagnosis and management of congenital Dyserythropoietic Anemias. Expert Rev Hematol. 2016;9:28396. https://doi.org/10.1586/17474086.2016.1131608.

6. Fermo, E., Vercellati, C., Marcello, A.P., Zaninoni, A., Aytac, S., Cetin, M., Capolsini, I., Casale, M., Paci, S., Zanella, A. et al. Clinical and molecular spectrum of glucose-6-phosphate isomerase deficiency. Report of 12 New Cases. Front. Physiol. 2019. doi:https://doi.org/10.3389/fphys.2019. 00467.

7. Bianchi P, Fermo E, Lezon-Geyda K, van Beers EJ, Morton HD, Barcellini W, Glader B, Chonat S, Ravindranath Y, Newburger PE, et al. Genotypephenotype correlation and molecular heterogeneity in pyruvate kinase deficiency. Am J Hematol. 2020;95:472-82. https://doi.org/10.1002/ajh. 25753.

8. Perrotta S, Gallagher PG, Mohandas N. Hereditary spherocytosis. Lancet. 2008;372:1411-26. https://doi.org/10.1016/S0140-6736(08)61588-3.

9. Narla J, Mohandas N. Red cell membrane disorders. Int J Lab Hematol. 2017;39(Suppl 1):47-52. https://doi.org/10.1111/ijlh.12657.

10. Mariani M, Barcellini W, Vercellati C, Marcello AP, Fermo E, Pedotti $P$, Boschetti C, Zanella A. Clinical and hematologic features of 300 patients affected by hereditary spherocytosis grouped according to the type of the membrane protein defect. Haematologica. 2008;93:1310-7. https:// doi.org/10.3324/haematol.12546.

11. Zaninoni A, Fermo E, Vercellati C, Consonni D, Marcello AP, Zanella A, Cortelezzi A, Barcellini W, Bianchi P. Use of laser assisted optical rotational cell analyzer (LoRRca MaxSis) in the diagnosis of RBC membrane disorders, enzyme defects, and congenital dyserythropoietic anemias: a monocentric study on 202 patients. Front Physiol. 2018;9:451. https://doi.org/10. 3389/fphys.2018.00451.

12. He B-J, Liao L, Deng Z-F, Tao Y-F, Xu Y-C, Lin F-Q. Molecular genetic mechanisms of hereditary spherocytosis: current perspectives. Acta Haematol. 2018;139:60-6. https://doi.org/10.1159/000486229.

13. Wang X, Zhang A, Huang M, Chen L, Hu Q, Lu Y, Cheng L. Genetic and clinical characteristics of patients with hereditary spherocytosis in Hubei Province of China. Front Genet. 2020;11:953. https://doi.org/10.3389/ fgene.2020.00953.

14. Iolascon A, Andolfo I, Barcellini W, Corcione F, Garçon L, De Franceschi L, Pignata C, Graziadei G, Pospisilova D, Rees DC, et al. Recommendations regarding splenectomy in hereditary hemolytic anemias. Haematologica. 2017;102:1304-13. https://doi.org/10.3324/haematol.2016.161166.

15. Andolfo I, Alper SL, De Franceschi L, Auriemma C, Russo R, De Falco L, Vallefuoco F, Esposito MR, Vandorpe DH, Shmukler BE, et al. Multiple clinical forms of dehydrated hereditary stomatocytosis arise from mutations in PIEZO1. Blood. 2013;121(3925-3935):S1-12. https://doi.org/10.1182/ blood-2013-02-482489.

16. Andolfo I, Russo R, Manna F, Shmukler BE, Gambale A, Vitiello G, De Rosa G, Brugnara C, Alper SL, Snyder LM, et al. Novel gardos channel mutations linked to dehydrated hereditary stomatocytosis (Xerocytosis). Am J Hematol. 2015;90:921-6. https://doi.org/10.1002/ajh.24117.

17. Andolfo I, Russo R, Gambale A, Iolascon A. Hereditary stomatocytosis: an underdiagnosed condition. Am J Hematol. 2018;93:107-21. https://doi. org/10.1002/ajh.24929. 
18. Bruce L, Guizouarn H, Burton NM, Gabillat N, Poole J, Flatt JF, Brady RL, Borgese F, Delaunay J, Stewart GW. The monovalent cation leak in overhydrated stomatocytic red blood cells results from amino acid substitutions in the Rh-associated glycoprotein. Blood. 2009;113:1350-7. https://doi. org/10.1182/blood-2008-07-171140.

19. Fermo E, Bogdanova A, Petkova-Kirova P, Zaninoni A, Marcello AP, Makhro A, Hänggi P, Hertz L, Danielczok J, Vercellati C, et al. 'Gardos Channelopathy': a variant of hereditary stomatocytosis with complex molecular regulation. Sci Rep. 2017;7:1744. https://doi.org/10.1038/s41598-017-01591-w.

20. Bisharat N, Omari H, Lavi I, Raz R. Risk of Infection and death among postsplenectomy patients. J Infect. 2001;43:182-6. https://doi.org/10.1053/ jinf.2001.0904.

21. Schilling RF, Gangnon RE, Traver MI. Delayed adverse vascular events after splenectomy in hereditary spherocytosis. J Thromb Haemost JTH. 2008;6:1289-95. https://doi.org/10.1111/j.1538-7836.2008.03024.x.

22. Crary SE, Buchanan GR. Vascular complications after splenectomy for hematologic disorders. Blood. 2009;114:2861-8. https://doi.org/10.1182/ blood-2009-04-210112.

23. Guizzetti L. Total versus partial splenectomy in pediatric hereditary spherocytosis: a systematic review and meta-analysis. Pediatr Blood Cancer. 2016;63:1713-22. https://doi.org/10.1002/pbc.26106.

24. Chaplin $\mathrm{H}$, Zarkowsky HS. Combined sickle cell disease and autoimmune hemolytic anemia. Arch Intern Med. 1981;141:1091-3.

25. Khaled MB, Ouederni M, Sahli N, Dhouib N, Abdelaziz AB, Rekaya S, Kouki R, Kaabi H, Slama H, Mellouli F, et al. Predictors of autoimmune hemolytic anemia in beta-thalassemia patients with underlying red blood cells autoantibodies. Blood Cells Mol Dis. 2019;79: 102342. https://doi.org/10. 1016/j.bcmd.2019.102342.

26. Stewart GW, Amess JA, Eber SW, Kingswood C, Lane PA, Smith BD, Mentzer WC. Thrombo-embolic disease after splenectomy for hereditary stomatocytosis. Br J Haematol. 1996;93:303-10. https://doi.org/10.1046/j. 1365-2141.1996.4881033.x.

27. Perel Y, Dhermy D, Carrere A, Chateil JF, Bondonny JM, Micheau M, Barbier R. Portal Vein thrombosis after splenectomy for hereditary stomatocytosis in childhood. Eur J Pediatr. 1999;158:628-30. https://doi.org/10.1007/ s004310051165.

28. Jaïs X, Till SJ, Cynober T, loos V, Garcia G, Tchernia G, Dartevelle P, Simonneau $G$, Delaunay J, Humbert M. An extreme consequence of splenectomy in dehydrated hereditary stomatocytosis: gradual thrombo-embolic pulmonary hypertension and lung-heart transplantation. Hemoglobin. 2003;27:139-47. https://doi.org/10.1081/hem-120023377.

29. Grace RF, Mark Layton D, Barcellini W. How we manage patients with pyruvate kinase deficiency. Br J Haematol. 2019;184:721-34. https://doi. org/10.1111/bjh.15758.

30. Grace RF, Barcellini W. Management of pyruvate kinase deficiency in children and adults. Blood. 2020;136:1241-9. https://doi.org/10.1182/blood. 2019000945.

31. Grace RF, Bianchi P, van Beers EJ, Eber SW, Glader B, Yaish HM, Despotovic JM, Rothman JA, Sharma M, McNaull MM, et al. Clinical spectrum of pyruvate kinase deficiency: data from the pyruvate kinase deficiency natural history study. Blood. 2018;131:2183-92. https://doi.org/10.1182/ blood-2017-10-810796.

32. Grace RF, Rose C, Layton DM, Galactéros F, Barcellini W, Morton DH, van Beers EJ, Yaish H, Ravindranath Y, Kuo KHM, et al. Safety and efficacy of mitapivat in pyruvate kinase deficiency. N Engl J Med. 2019;381:933-44. https://doi.org/10.1056/NEJMoa1902678.

33. ClinicalTrials.Gov [Internet]. Bethesda (MD): National Library of Medicine (US). 2000 Feb 29 - Identifier NCT04105166, Gene Therapy for Pyruvate Kinase Deficiency (PKD); 2021 Apr 18 [Cited 2021 Apr 18]. Available from: https://Clinicaltrials.Gov/Ct2/Show/NCT04105166?Cond=pyruvate+ kinase\&draw $=2 \&$ rank $=4$.

34. Al-Samkari, H.; Beers, E.J. van; Kuo, K.H.M.; Barcellini, W.; Bianchi, P.; Glenthøj, A.; Pereira, M. del M.M.; Wijk, R. van; Glader, B.; Grace, R.F. The Variable Manifestations of Disease in Pyruvate Kinase Deficiency and Their Management. Haematologica 2020, 105, 2229-2239, doi:https://doi. org/10.3324/haematol.2019.240846.

35. Boscoe AN, Yan Y, Hedgeman E, van Beers EJ, Al-Samkari H, Barcellini W, Eber SW, Glader B, Yaish HM, Chonat S, et al. Comorbidities and complications in adults with pyruvate kinase deficiency. Eur J Haematol. 2021;106:484-92. https://doi.org/10.1111/ejh.13572.
36. Petz LD. "Least Incompatible" Units for Transfusion in Autoimmune Hemolytic Anemia: Should We Eliminate This Meaningless Term? A Commentary for Clinicians and Transfusion Medicine Professionals. Transfusion (Paris). 2003:43:1503-7. https://doi.org/10.1046/j.1537-2995.2003.00583.x.

37. Ziman A, Cohn C, Carey PM, Dunbar NM, Fung MK, Greinacher A, Stanworth S, Heddle NM, Delaney M. The Biomedical Excellence for Safer Transfusion (BEST) Collaborative Warm-Reactive (Immunoglobulin G) Autoantibodies and Laboratory Testing Best Practices: Review of the Literature and Survey of Current Practice. Transfusion (Paris). 2017;57:463-77. https://doi.org/10.1111/trf.13903.

38. Schröter W, Eber SW, Bardosi A, Gahr M, Gabriel M, Sitzmann FC. Generalised Glucosephosphate Isomerase (GPI) deficiency causing haemolytic anaemia, neuromuscular symptoms and impairment of granulocytic function: a new syndrome due to a new stable GPI variant with diminished specific activity (GPI Homburg). Eur J Pediatr. 1985;144:301-5. https://doi.org/10.1007/BF00441768.

39. Kugler W, Breme K, Laspe P, Muirhead H, Davies C, Winkler H, Schröter W, Lakomek M. Molecular basis of neurological dysfunction coupled with haemolytic anaemia in human glucose-6-phosphate isomerase (GPI) deficiency. Hum Genet. 1998;103:450-4. https://doi.org/10.1007/s0043 90050849.

40. Jamwal, M.; Aggarwal, A.; Das, A.; Maitra, A.; Sharma, P.; Krishnan, S.; Arora, N.; Bansal, D.; Das, R. Next-generation sequencing unravels homozygous mutation in glucose-6-phosphate isomerase, GPIc.1040G >A (p.Arg347His) causing hemolysis in an Indian Infant. Clin. Chim. Acta Int. J. Clin. Chem. 2017, 468, 81-84, doi:https://doi.org/10.1016/j.cca.2017.02. 012.

41. Kedar, P.S., Dongerdiye, R., Chilwirwar, P., Gupta, V., Chiddarwar, A., Devendra, R., Warang, P., Prasada, H., Sampagar, A., Bhat, S., et al. Glucose phosphate isomerase deficiency: high prevalence of p.Arg347His mutation in indian population associated with severe hereditary non-spherocytic hemolytic anemia coupled with neurological dysfunction. Indian J. Pediatr. 2019, 86, 692-699, doi:https://doi.org/10.1007/s12098-019-02928-1.

42. Walker JI, Morgan MJ, Faik P. Structure and organization of the human glucose phosphate isomerase gene (GPI). Genomics. 1995;29:261-5. https://doi.org/10.1006/geno.1995.1241.

43. Barcellini W, Zaninoni A, Gregorini Al, Soverini G, Duca L, Fattizzo B, Giannotta JA, Pedrotti P, Vercellati C, Marcello AP, et al. Iron overload in congenital haemolytic anaemias: role of hepcidin and cytokines and predictive value of Ferritin and transferrin saturation. Br J Haematol. 2019;185:523-31. https://doi.org/10.1111/bjh.15811.

44. Orosz F, Oláh J, Ovádi J. Triosephosphate isomerase deficiency: new insights into an enigmatic disease. Biochim Biophys Acta. 2009;1792:1168-74. https://doi.org/10.1016/j.bbadis.2009.09.012.

45. Harris C, Nelson B, Farber D, Bickel S, Huxol H, Asamoah A, Morton R. Child neurology: triosephosphate isomerase deficiency. Neurology. 2020;95:e3448-51. https://doi.org/10.1212/WNL.0000000000010745.

46. Heimpel H. Congenital Dyserythropoietic Anemias: epidemiology, clinical significance, and progress in understanding their pathogenesis. Ann Hematol. 2004;83:613-21. https://doi.org/10.1007/s00277-004-0892-5.

47. Iolascon A, Russo R, Delaunay J. Congenital dyserythropoietic anemias. Curr Opin Hematol. 2011;18:146-51. https://doi.org/10.1097/MOH.0b013 e32834521b0.

48. Iolascon A, Heimpel H, Wahlin A, Tamary H. Congenital Dyserythropoietic Anemias: molecular insights and diagnostic approach. Blood. 2013;122:2162-6. https://doi.org/10.1182/blood-2013-05-468223.

49. Iolascon A, Andolfo I, Russo R. Congenital dyserythropoietic anemias. Blood. 2020;136:1274-83. https://doi.org/10.1182/blood.2019000948.

50. Heimpel H, Kellermann K, Neuschwander N, Högel J, Schwarz K. The morphological diagnosis of congenital dyserythropoietic anemia: results of a quantitative analysis of peripheral blood and bone marrow cells. Haematologica. 2010;95:1034-6. https://doi.org/10.3324/haematol.2009. 014563.

51. Iolascon A, Esposito MR, Russo R. Clinical aspects and pathogenesis of congenital dyserythropoietic anemias: from morphology to molecular approach. Haematologica. 2012;97:1786-94. https://doi.org/10.3324/ haematol.2012.072207.

52. Tamary H, Offret H, Dgany O, Foliguet B, Wickramasinghe SN, Krasnov T, Rumilly F, Goujard C, Fénéant-Thibault M, Cynober T, et al. Congenital dyserythropoietic anaemia, type I, in a Caucasian Patient with Retinal Angioid Streaks (Homozygous Arg 1042Trp Mutation in Codanin-1). Eur 
J Haematol. 2008;80:271-4. https://doi.org/10.1111/j.1600-0609.2007. 01004.x.

53. Bianchi P, Fermo E, Vercellati C, Boschetti C, Barcellini W, lurlo A, Marcello AP, Righetti PG, Zanella A. Congenital Dyserythropoietic Anemia Type II (CDAll) Is Caused by Mutations in the SEC23B Gene. Hum Mutat. 2009;30:1292-8. https://doi.org/10.1002/humu.21077.

54. Schwarz K, Iolascon A, Verissimo F, Trede NS, Horsley W, Chen W, Paw BH, Hopfner K-P, Holzmann K, Russo R, et al. Mutations affecting the secretory COPII coat component SEC23B cause congenital dyserythropoietic anemia type II. Nat Genet. 2009;41:936-40. https://doi.org/10.1038/ng.405.

55. Liljeholm M, Irvine AF, Vikberg A-L, Norberg A, Month S, Sandström H, Wahlin A, Mishima M, Golovleva I. Congenital dyserythropoietic anemia type III (CDA III) is caused by a mutation in kinesin family member, KIF23. Blood. 2013;121:4791-9. https://doi.org/10.1182/blood-2012-10-461392.

56. Arnaud L, Saison C, Helias V, Lucien N, Steschenko D, Giarratana M-C, Prehu C, Foliguet B, Montout L, de Brevern AG, et al. A Dominant mutation in the gene encoding the erythroid transcription factor KLF1 causes a congenital dyserythropoietic anemia. Am J Hum Genet. 2010;87:721-7. https://doi.org/10.1016/j.ajhg.2010.10.010.

57. Nichols KE, Crispino JD, Poncz M, White JG, Orkin SH, Maris JM, Weiss MJ. Familial Dyserythropoietic Anaemia and thrombocytopenia Due to an inherited mutation in GATA1. Nat Genet. 2000;24:266-70. https://doi.org/ 10.1038/73480.

58. Bianchi P, Schwarz K, Högel J, Fermo E, Vercellati C, Grosse R, van Wijk R, van Zwieten, R, Barcellini W, Zanella A et al. Analysis of a cohort of 101 CDAll patients: description of 24 new molecular variants and genotypephenotype correlations. Br J Haematol. 2016;175:696-704. https://doi. org/10.1111/bjh.14271.

59. Uygun V, Russo R, Karasu G, Daloğlu H, Iolascon A, Yeşilipek A. Hematopoietic stem cell transplantation in congenital dyserythropetic anemia type II: a case report and review of the literature. J Pediatr Hematol Oncol. 2020;42:e507-10. https://doi.org/10.1097/MPH.0000000000001612.

60. De Rosa, G., Andolfo, I., Marra, R., Manna, F., Rosato, B.E., Iolascon, A., Russo, R. RAP-011 rescues the disease phenotype in a cellular model of congenital dyserythropoietic anemia type II by Inhibiting the SMAD2-3 pathway. Int. J. Mol. Sci. 2020, 21, doi:https://doi.org/10.3390/ijms21155577.
61. Fenaux P, Platzbecker U, Mufti GJ, Garcia-Manero G, Buckstein R, Santini V, Díez-Campelo M, Finelli C, Cazzola M, Ilhan O, et al. Luspatercept in patients with lower-risk myelodysplastic syndromes. N Engl J Med. 2020;382:140-51. https://doi.org/10.1056/NEJMoa1908892.

62. Cappellini MD, Viprakasit V, Taher AT, Georgiev P, Kuo KHM, Coates T, Voskaridou E, Liew H-K, Pazgal-Kobrowski I, Forni GL, et al. A Phase 3 trial of luspatercept in patients with transfusion-dependent $\beta$-Thalassemia. N Engl J Med. 2020;382:1219-31. https://doi.org/10.1056/NEJMoa1910182.

63. Bianchi P, Vercellati $C$, Fermo E. How will next generation sequencing (NGS) improve the diagnosis of congenital hemolytic anemia? Ann Transl Med. 2020;8:268. https://doi.org/10.21037/atm.2020.02.151.

64. Motta I, Filocamo M, Poggiali E, Stroppiano M, Dragani A, Consonni D, Barcellini W, Gaidano G, Facchini L, Specchia G, et al. A Multicentre observational study for early diagnosis of gaucher disease in patients with splenomegaly and/or thrombocytopenia. Eur J Haematol. 2016;96:352-9. https://doi.org/10.1111/ejh.12596.

65. Motta I, Consonni D, Stroppiano M, Benedetto C, Cassinerio E, Tappino B, Ranalli P, Borin L, Facchini L, Patriarca A, et al. Predicting the probability of Gaucher disease in subjects with splenomegaly and thrombocytopenia. Sci Rep. 2021;11:2594. https://doi.org/10.1038/s41598-021-82296-z.

66. Fattizzo B, Giannotta J, Zaninoni A, Kulasekararaj A, Cro L, Barcellini W. Small paroxysmal nocturnal hemoglobinuria clones in autoimmune hemolytic anemia: clinical implications and different cytokine patterns in positive and negative patients. Front Immunol. 2020;11:1006. https://doi. org/10.3389/fimmu.2020.01006

67. Fattizzo B, Ireland R, Dunlop A, Yallop D, Kassam S, Large J, Gandhi S, Muus P, Manogaran C, Sanchez K, et al. Clinical and prognostic significance of small paroxysmal nocturnal hemoglobinuria clones in myelodysplastic syndrome and aplastic anemia. Leukemia. 2021. https://doi.org/10.1038/ s41375-021-01190-9.

\section{Publisher's Note}

Springer Nature remains neutral with regard to jurisdictional claims in published maps and institutional affiliations.
Ready to submit your research? Choose BMC and benefit from:

- fast, convenient online submission

- thorough peer review by experienced researchers in your field

- rapid publication on acceptance

- support for research data, including large and complex data types

- gold Open Access which fosters wider collaboration and increased citations

- maximum visibility for your research: over $100 \mathrm{M}$ website views per year

At BMC, research is always in progress.

Learn more biomedcentral.com/submissions 